\title{
The dark-interval threshold as a function of age'
}

ROBERT H. POLLACK, RICHARD I. PTASHNE, and DOROTHY J. CARTER, Institute for Juvenile Research, Chicago, III. 60611

The threshold for the dark interval between two flashes was inlestigated in 100 elementary school children, age 6-10. It was found that the threshold decreased with chronological age, 'a finding attributed to physiological aging of the liswal receptor system producing diminished persistence of the initial stimulus.

Pollack (1968) has put forth a two-process theory to explain age clianges in visual perception. One of these processes, nondevelopmental in nature, involves a progressive loss in receptor sensitivity due to physiological aging. The other process is "developmental" in that age changes are related to central cognitive functions and abilities which are hierarchically organized. Within the framework of this theory, those phenomena which show nondevelopmental age changes (Type I) are not correlated with intellectual ability, but appear to be related directly to receptor efficiency and various stimulus variables such as intensity, duration, contrast, and orientation. Those phenomena showing developmental age changes (Type II) are correlated with intellectual ability and do not depend as much upon classical stimulus variation. Presentation of such phenomena usually involves a sequence of discrete stimulus events, registered by the $S$ as traces, which are then centrally compared and contrasted.

It is assumed that in making judgments about two stimuli presented in rapid succession, the individual early in life makes use of the physical persistence of the initial stimulus to make what is virtually a simultaneous comparison. As this stimulus persistence weakens as a function of aging in the receptor system, comparison comes to be based upon the higher-order cognitive function of comparing the trace of the vanished initial stimulus with the second stimulus. This transition was demonstrated by Pollack (1966) in a study dealing with apparent movement. The temporal range of apparent movement decreased between the ages of 6 and 9 , but increased again beyond the age of 9 . Correlation with IQ was nonsignificant for the 6- to 9-year-olds, but positive and significant for the 10- and 11-year-olds. The pattern of results obtained in this experiment was very similar to that obtained in an earlier study by Pollack (1960), concerning the frequency of occurrence of figural aftereffects following brief inspection.

The present experiment was designed to test further the hypothesis that stimulus persistence declines with age. The dark-interval threshold (DIT) can be thought of as a simplified version of the critical flicker frequency (CFF), in which two flashes of light are presented in quick temporal succession with a varying interflash interval. The $S$ is simply asked to report whether he can detect a dark interval between the flashes. At the present time, data on the DIT are very scarce. In general, results from studies of CFF have shown a decrease in CFF (poorer performance) beyond the age of 14. Cross (1963) performed a study of CFF with an age range of 6 to 12 years. She found a significant increase in CFF (better performance) with age. Correlation between CFF and IQ was not significant in her 6-, 8-, and 10-year-old groups. If stimulus persistence does weaken as a function of physiological aging of the receptor system, one would expect this increase in performance since it would allow for better resolution of individual flashes. This study also indicates that, by puberty, intelligence may begin to play a role, and that CFF should begin to decline beyond the age of 12 as the cognitive function of taking into account traces of stimuli interferes with perception of the dark interval. A study by Misiak (1951) also lends support to these notions. There was a nonsignificant increase in CFF between his 7-11 and 12-16 year-old groups. This suggests that up to some point in the 12-16 year age group, performance could have actually been improving, but the gross grouping of ages may have obscured this. From the 12-16 year age group on. CFF decreased. The relationship of CFF to intellectual functioning is at present unclear. Positive, negative, and zero correlations have been obtained between CFF and a variety of intelligence tests (Landis \& Hamwi, 1956; Wilson, 1963).

If stimulus persistence does decrease with age, one would expect the DIT to decrease with age, as the persistence of the first stimulus bridges less and less of the dark interstimulus interval. At some point in the age range, as initial stimulus persistence continues to decline, a new, analogous process, the interfering presence of the stimulus trace, could replace it, perhaps causing the DIT to rise as age increases further. Due to the time limitations of the school year, this preliminary report permitted testing of Ss only through age 10, and thus only the decline in DIT was expected to appear in the data.

\section{Subjects ${ }^{2}$}

\section{METHOD}

One hundred suburban school children, age 6-10 served as Ss. Each age was represented by 10 males and 10 females, all with $20 / 30$ uncorrected vision, or better, as determined by the Master Orthorater.

Apparatus

Flashes were presented binocularly in a 3-channel electronic tachistoscope (Model G) manufactured by Scientific Prototype Manufacturing Corporation of New York. Channel 1 and a back lighter matched for brightness to Channel 1 served as the flash sources. Each flash was generated by the illumination passing through an aperture $6 \mathrm{~mm}$ in diameter cut from the middle of a black background card. The visual angle of the flash was $18 \mathrm{~min}$ $40 \mathrm{sec}$. Flash 1 was generated from Channel 1, followed by a period of no illumination (dependent variable). Flash 2 was generated by the back lighter. Both stimuli were thus presented through the same aperture. Three flash brightness levels were used: $8.84 \mathrm{ft}-\mathrm{c}, 4.37 \mathrm{ft}-\mathrm{c}$, and $2.59 \mathrm{ft}-\mathrm{c}$, as measured by a Macbeth Illuminometer at the eye piece.

Procedure

Each $S$ was dark adapted for 5 min. He was then shown examples of obvious double and single flashes. He was instructed to report " 2 " whenever he could detect a dark interval between the flashes, and to report "1" when he saw one flash or failed to detect any dark interval. The light source was turned on periodically between trials to provide a target for $S$ in the middle of the visual field. Thresholds were obtained from five ascending and five descending trials presented in counterbalanced order, with interflash intervals ranging from 0 to $250 \mathrm{msec}$, presented in 10 msec steps. A trial ended when $S$ reported either three consecutive "2s" or " $1 \mathrm{~s}$." The three brightness conditions were given to all Ss in counterbalanced order. Flash durations 1 and 2 were kept constant at $20 \mathrm{msec}$.

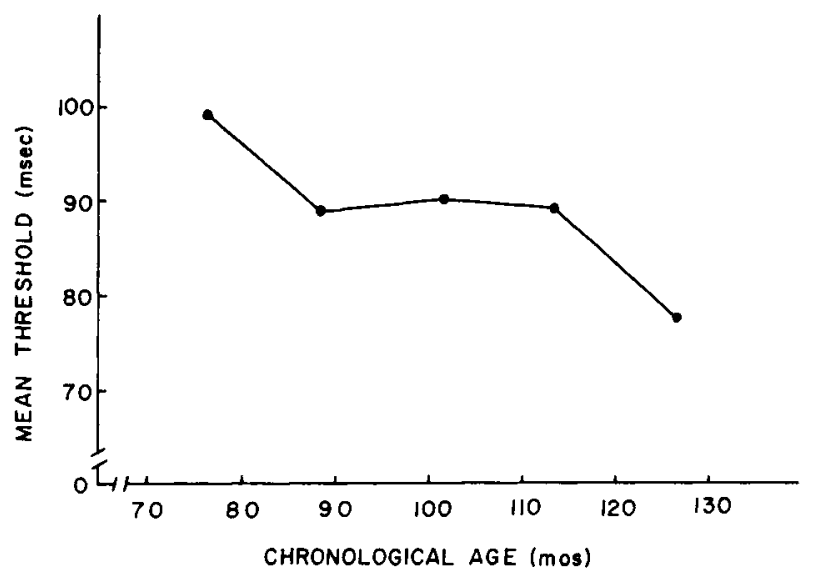

Fig. 1. Mean dark interval threshold as a function of age. 


\section{RESULTS AND DISCUSSION}

Since an initial analysis revealed no sex differences, boys' and girls' scores were combined for all subsequent analyses. Bartlett's test for homogeneity of variance revealed that group variances were not homogeneous, and thus Wilson's (1956) distribution-free analysis of variance, a nonparametric measure, was used. The 2 by 2 analysis $-\mathrm{Age}$ by Brightness conditions-yielded a significant effect of Age $\left(\chi^{2}=10.13, \mathrm{df}=4, \mathrm{p}<.05\right)$, but no significant effect of Brightness $\left(\chi^{2}=1.68, \mathrm{df}=2\right)$ or interaction $\left(\chi^{2}=6.19\right.$, $\mathrm{df}=8$ ). Limitations of the apparatus prevented using a wider range of brightness values, which might have produced a significant effect. The lack of any significant brightness effects permitted scores for each $\mathbf{S}$ on all three brightness conditions to be averaged to give one grand score. The means of these scores appear in Fig. 1 .

To examine the age trend more closely, t-tests were run between all pairs of age groups. One-tailed comparisons yielded significant differences between six of the 10 pairs in the expected direction; i.e., a decline in threshold with increasing age.

Correlation between chronological age (CA) and mental age (MA) was $.5694(\mathrm{~N}=51, \mathrm{p}<.01)^{3}$; $\mathrm{r}$ between CA and DIT was $-.25(\mathrm{~N}=100, \mathrm{p}<.05)$; and $\mathrm{r}$ between MA and DIT was .0451 ( $\mathrm{N}=51, \mathrm{NS}$ ). Thus $\mathrm{CA}$, not MA, is the major variable associated with the age changes encountered here. The effects of $C A$ and MA appear to be opposite in direction. Rank difference correlations with IQ within grade, while not significant, indicate an increasing positive correlation as age increases.

The results are consistent with the notion that stimulus persistence as measured by DIT declines with age. For the present age range, DIT has all the characteristics of a Type 1 phenomenon. The decline in DIT with age can be accounted for by the effects of physiological aging of the receptor system on the reception of light stimuli impinging on it. The rank difference correlations, though nonsignificant, were in a direction which indicates that with the more intelligent children, memory traces from the first flash may have begun to interfere with the dark interval to produce higher thresholds. The experiment will be extended to older children, to discover at what age the expected rise in DIT as a function of increasing higher-order cognitive functioning might occur.

\section{REFERENCES}

CROSS, J. P. Relation of age and mental growth to the CFF response in children. Child Development, 1963, 34(3), 739-744.

LANDIS, C., \& HAMWI, V. Critical flicker frequency, age and intelligence. American Journal of Psychology, 1956, 69, 459-461.

MISIAK, H. The decrease in critical flicker with age. Science, 1951, 113, 551-552.

POLLACK, R. H. Figural aftereffects as a function of age. Acta Psychologica, $1960,17,5,417-423$.

POLLACK, R. H. Temporal range of apparent movement as a function of age and intelligence. Psychonomic Science, 1966, 5, 243-244.

POLLACK, R. H. Some implications of ontogenetic changes in perception. In D. Elkind and J. Flavell (Eds.), Essays in cognitive development: Studies in honor of Jean Piaget. New York: Oxford University Press, in press. WILSON, K. V. A distribution free test of analysis of variance hypotheses. Psychological Bulletin, 1956, 53, 96-101.

WILSON, T. R. Flicker fusion frequency, age and intelligence. Gerontologia, $1963,7,200-208$

\section{NOTES}

1. This research was supported by Grant No. HD 01433 awarded by the National Institute of Child Health and Human Development.

2. We are grateful for the cooperation of Mr. Darrell Holsteen, Superintendent of School District 89, Glen Ellyn, Illinois and Mr. Ronald Howard, Principal of Arbor View School, Glen Ellyn, Illinois.

3. The measure of intelligence was the Lorge Thorndike IQ Test. Scores were not available for $\mathrm{Ss}$ in the 6-and 7-year-old groups. 